\title{
Clinicopathologic and prognostic features of breast cancer in young women: a series from North of Morocco
}

\author{
Joaira Bakkach ${ }^{1 *} \mathbb{D}$, Mohamed Mansouri ${ }^{1,2}$, Touria Derkaoui ${ }^{1}$, Ali Loudiyi ${ }^{2}$, Mohamed Fihri $^{3}$, Samia Hassani ${ }^{1}$, \\ Amina Barakat ${ }^{1}$, Naima Ghailani Nourouti ${ }^{1}$ and Mohcine Bennani Mechita ${ }^{1}$
}

\begin{abstract}
Background: Literature data reported a higher frequency of breast cancer in young women (BCYW) in developing countries. BCYW is associated with delayed diagnosis, aggressive biology and poor prognosis. However, our knowledge of biological profile, treatment received and outcome of young patients is still limited in Morocco. We propose to analyze clinicopathologic, therapeutic and prognostic features of BCYW among a series of patients native and/or inhabitant of North of Morocco.

Methods: We carried out a retro-prospective study of 331 infiltrating breast cancer cases registered between January 2010 and December 2015. Details of tumor pathology, treatment and outcome were collected. Disease-Free Survival (DFS) and Overall Survival (OS) were assessed by Kaplan-Meier analysis.

Results: A total of 82 patients were diagnosed with breast cancer at the age of 40 or younger (24.8\%). Median age was 36 years. More than one quarter (26\%) of patients had family history of breast or ovarian cancer. Advanced stages accounted for $34.2 \%$ of cases. Median tumor diameter was $2.8 \mathrm{~cm}$. Intermediate and high-grade tumors represented $47.6 \%$ and $40.2 \%$, respectively. Nodal involvement was present in $58.5 \%$ and lymphovascular invasion was found in 47. $7 \%$ of the patients. About two thirds (66.2\%) of tumors were hormone receptor positive, $29.2 \%$ over-expressed HER2 receptor and $23 \%$ were triple negative. Patients underwent breast conserving surgery in $38.2 \%$ of cases, $61.7 \%$ were offered adjuvant chemotherapy and $84.6 \%$ received hormone therapy. Five-year DFS and OS were respectively 88.9\% and $75.6 \%$. Locoregional recurrence occurred in $2.8 \%$ of cases and $8.3 \%$ of patients developed distant metastases.
\end{abstract}

Conclusion: Our findings are in accordance with previous studies that have shown a higher frequency of breast cancer among Moroccan young women. In line with literature data, clinicopathologic profile seems to be aggressive and prognosis is pejorative in our series.

Keywords: Breast cancer, Young women, BRCA1, BRCA2, Aggressive biology, Poor prognosis, Survival analysis

\section{Background}

Overall, breast cancer risk increases with the age. Incidence rates are shown to be lower among young women and the peak is within the age range of $65-74$ years in more developed countries [1]. However in Morocco, the median age at onset for breast cancer is decade younger. According to the Greater Casablanca Cancer Registry report 2012, the peak incidence is at the age group 40-

\footnotetext{
* Correspondence: joairaa@gmail.com

${ }^{1}$ Human Genomic Research Laboratory, Faculty of Sciences and Techniques of Tangier, University Abdelmalek Essaâdi, Tangier, Morocco

Full list of author information is available at the end of the article
}

49 years [2]. Moreover, hospital-based series reported that breast cancer in young women (BCYW) do account for 8 to $25.4 \%$ [3-6], whereas this frequency does not exceed $7 \%$ in developed countries [7].

Young women deserve a particular attention because of the unique and complex challenges that these women are faced with [8]. These breast cancer patients have to deal with many issues related to fertility, self-image, psychosocial distress and professional integration. On the other hand, breast cancer in this age category tends to exhibit more aggressive features than that arising in 
older women [9-14], which makes the situation more difficult to handle.

BCYW is often associated with delayed diagnosis, aggressive biology, high relapse risk and poor survival [15-17]. The reason for this aggressiveness remains unclear. Historically, young age has been shown to be an independent predictor factor for poor prognosis [13, 18, 19]. However, recently with the emergence of molecular classification, this association with young age has disappeared in some studies [14, 20]. Currently, it is controversial whether $\mathrm{BCYW}$ is a unique biologic entity or it just reflects an over-representation of more aggressive molecular subtypes [21].

Young age for breast cancer occurrence often suggests an underlying genetic predisposition especially mutations in BRCA1/2 genes and less frequently in p53. Overall, BRCA1/2 genetic alterations may explain 10\% of breast carcinomas arising in young women [22], but in studies from Arab countries much higher proportions have been reported [23, 24]. In Morocco, the young age for breast cancer diagnosis also strongly suggests that genetic factors could be involved.

We are conducting a genetic study to explore BRCA1 and BRCA2 mutations among breast cancer patients diagnosed at the age of 40 years or younger. This is the first genetic study including a case-series from North of Morocco. In this paper, we present a description of clinicopathologic, therapeutic and prognostic features among these south Mediterranean patients seen at the Oncology Clinic AL AMAL in Tangier, the only institution specialized in diagnosis and treatment of cancers available in the North Moroccan area at the beginning of the study.

\section{Methods}

A total of 331 patients with invasive breast carcinoma were referred to the Oncology Clinic AL AMAL in Tangier between January 2010 and December 2015. Only patients diagnosed with breast cancer at the age of 40 or younger were recruited 82 (24.8\%).

Medical records were reviewed and details of clinical characteristics, tumor pathology and treatment received were recorded. Family history, ethnic origin and any missing information were completed at follow-up visits. Patients with bilateral breast cancer were recorded only once.

Tumors were classified by means of TNM system 2010 and regrouped according to the American Joint Committee on Cancer stages (AJCC 2010). Histologic grading was performed according to SBR classification modified by Elston and Elliss (mSBR). Hormone receptors (HR, Estrogen ER and Progesterone PR) expression was evaluated based on percentage of tumor cells nuclear staining by the immunohistochemical method
(IHC). The threshold for ER and PR positivity was $\geq 1 \%$. HER2 (Human Epidermal growth factor Receptor 2) expression was processed immunohistochemicaly from paraffin-embedded cancer tissue using the HercepTest. Tumors scored $2^{+}$were completed by FISH or CISH methods.

Patients were followed until 22 August 2016. The follow-up schedule was: every 4 months during the first 2 years, every 6 months for the next $2-5$ years and every year thereafter. All patients who were not reviewed in the last visit were contacted again.

Five-year overall survival (OS) and Disease-free survival (DFS) were assessed using the Kaplan-Meier analysis. These were defined from the date of diagnosis to any tumor relapse or last follow-up (DFS), and to death or last follow-up (OS). The Log-Rank test was used to assess statistical difference between survival curves according to stages. This test was performed at a $5 \%$ level.

Participants provided an informed written consent. This study received approval from the Biomedical Research Ethics Committee in the Faculty of Medicine and Pharmacy in Rabat (CERB).

\section{Results}

Among 331 patients diagnosed with breast cancer, 82 $(24.8 \%)$ were at the age of 40 years or younger. The median age at diagnosis was 36 years (inferior age limit of 26). Most (98.8\%) of the patients were Arabs or

Table 1 Demographic characteristics and family history (82 patients)

\begin{tabular}{ll}
\hline Parameter & Frequency \\
\hline Age at diagnosis & \\
$\quad$ Median & 36 years \\
$\leq 35$ & $45.1 \%$ \\
$>35$ & $54.9 \%$ \\
Ethnicity & \\
Arab & $68.3 \%$ \\
Amazigh & $30.5 \%$ \\
European & $1.2 \%$ \\
Family history & \\
Breast cancer in first- or second-degree relatives & $22 \%$ \\
Breast cancer in third- or fourth-degree relatives & $10 \%$ \\
Ovarian cancer & $4 \%$ \\
Other cancers & $42 \%$ \\
Absent & $22 \%$ \\
Eisinger Score & \\
$\leq 2$ & $14.6 \%$ \\
$3-4$ & $72 \%$ \\
$\geq 5$ & $13.4 \%$ \\
\hline
\end{tabular}


Amazighs (Berbers), whereas Europeans represent only $1.2 \%$ (Table 1).

More than one quarter (26\%) of patients reported having at least one first- or second-degree relative with breast or ovarian cancer. Eisinger scoring system has revealed that $85.4 \%$ of patients were eligible for genetic counseling (Score value $\geq 3$ ), of whom $15.7 \%$ had a score value more than 5 (Score value $\geq 5$ ) showing thus an excellent indication for BRCA1/2 genetic testing (Table 1).

Combined mammography and ultrasound showed abnormalities in $97.5 \%$ of patients, of whom $72.5 \%$ had lesions that were highly suspicious of malignancy (ACR/ BI-RADS category 5: American College of Radiology Breast Imaging-Reporting and Data System category 5). Only $2.5 \%$ were shown to be probably benign lesions (ACR 3) and were then reclassified during surveillance (Table 2). Clinically, $65.8 \%$ of patients were diagnosed with early-stage breast cancer, $22 \%$ locally advanced and $12.2 \%$ had metastatic disease. Of the whole series, distant visceral metastases were found in $14.6 \%$ of cases. Bone and brain metastases were seen in $9.8 \%$ and $2.4 \%$ respectively. Two patients had a personal history of

Table 2 Clinical characteristics (82 patients)

\begin{tabular}{|c|c|}
\hline Parameter & Frequency \\
\hline \multicolumn{2}{|l|}{ Presentation } \\
\hline Breast mass & $74.5 \%$ \\
\hline Axillary adenopathy & $6.4 \%$ \\
\hline Pain & $8.5 \%$ \\
\hline Induration & $6.4 \%$ \\
\hline Nipple retraction & $2.1 \%$ \\
\hline Screen detected & $2.1 \%$ \\
\hline \multicolumn{2}{|l|}{ Imaging findings } \\
\hline ACR3 & $2.5 \%$ \\
\hline ACR4 & $26.8 \%$ \\
\hline ACR5 & $70.7 \%$ \\
\hline \multicolumn{2}{|l|}{ Positive diagnosis } \\
\hline Biopsy & $71.8 \%$ \\
\hline Lympectomy & $28.2 \%$ \\
\hline \multicolumn{2}{|l|}{ Localization } \\
\hline Right & $38 \%$ \\
\hline Left & $62 \%$ \\
\hline \multicolumn{2}{|l|}{ Multifocal disease } \\
\hline Yes & $13.5 \%$ \\
\hline No & $86.5 \%$ \\
\hline \multicolumn{2}{|l|}{ Tumor size } \\
\hline Median & $2.8 \mathrm{~cm}$ \\
\hline$\leq 3$ & $57.3 \%$ \\
\hline$>3$ & $42.7 \%$ \\
\hline
\end{tabular}

contralateral breast cancer after a mean time interval of 118 months.

The histopathological characteristics are detailed in Table 3.

Patients with immediately operable (T1-T3N0N1) and immediately inoperable cancers (T4, N2-N3) represented $74.4 \%$ and $13.4 \%$ respectively. Those with metastatic disease at diagnosis accounted for $12.2 \%$ of cases. Of patients with immediately operable disease, $45.7 \%$ underwent breast-conserving surgery, whereas this proportion among those who had received neoadjuvant chemotherapy was only $10 \%$.

Patients with HR-positive disease received hormone therapy in $84.6 \%$ of cases. Use of 5 years of Tamoxifen

Table 3 Histopathological characteristics (82 patients)

\begin{tabular}{ll}
\hline Parameter & Frequency \\
\hline AJCC stages & \\
Early & $65.8 \%$ \\
Locally advanced & $22 \%$ \\
Metastatic & $12.2 \%$ \\
Histology & \\
Invasive carcinoma of No Special Type (NST) & $95.2 \%$ \\
Lobular & $2.4 \%$ \\
Mucinous & $2.4 \%$ \\
mSBR grading & \\
I & \\
II & $12.2 \%$ \\
III & $47.6 \%$ \\
Lymph node status & $40.2 \%$ \\
N- & \\
N+ & \\
Lymphovascular invasion & $41.5 \%$ \\
Present & $58.5 \%$ \\
Absent & \\
Intraductal component & \\
Present & \\
Mormone & \\
Positive & \\
Negativative & \\
\hline
\end{tabular}


alone was recorded for $69.7 \%$ of patients. The Suppression of Ovarian Function in combination with Tamoxifen was indicated definitively by ovarian irradiation for $6.1 \%$ of cases or reversely by means of Luteinizing HormoneReleasing Hormone (LH-RH) agonists (15.1\%). Patients who became definitively postmenopausal by the time of treatment after 2 or 3 years of Tamoxifen were switched to an Aromatase Inhibitor for the 2 or 3 years thereafter (9.1\%).

More information about treatment received is presented in Table 4.

During the total period of follow-up, $2.8 \%$ of patients developed isolated locoregional recurrence and $8.3 \%$ had distant metastases after a mean duration of 27.4 months (12-49 months). The estimated DFS at 5 years for nonmetastatic patients was $88.9 \%$ and OS for the whole case-series was $75.6 \%$. Early-stage breast cancer patients had superior OS at 5 years compared to advanced breast cancer patients $(85.2 \%$ Vs. $57.1 \%$, pvalue $=0.001<0.05)$ (Table 3, Figs. 1, 2 and 3).

\section{Discussion}

BCYW is a complex topic to discuss because there is no unified definition of "young age". The most used definitions place the limit at 35 or 40 years. This definition's variability creates non-homogeneity between studies, which complicates the interpretation of the results. In the present work we have chosen to define early onset breast cancer when diagnosed at the age of 40 or younger.

Table 4 Treatment modalities (82 patients)

\begin{tabular}{ll}
\hline Parameter & Frequency \\
\hline Surgery & \\
No & $16.7 \%$ \\
Yes & $83.3 \%$ \\
$\quad$ Radical & $61.8 \%$ \\
$\quad$ Conservative & $38.2 \%$ \\
Chemotherapy & \\
No & $9.1 \%$ \\
Yes & $90.9 \%$ \\
Neoadjuvant & $25 \%$ \\
Adjuvant & $61.7 \%$ \\
Palliative & $13.3 \%$ \\
Radiotherapy & \\
Yes & $73.4 \%$ \\
No & $26.6 \%$ \\
Hormonotherapy (HR+) & \\
Yes & $84.6 \%$ \\
No & $15.4 \%$ \\
\hline
\end{tabular}

Breast cancer is described as young women disease in Arab world and other developing nations like some African and Asian countries [25, 26]. Compared to that observed in western countries, median age for breast cancer diagnosis is a decade younger, and approximately two thirds of patients are aged under 50 [27]. Our results are in accordance with previous studies describing a higher proportion of early onset breast cancer in Morocco. Our frequency among women diagnosed at the age of 40 or younger $(24.8 \%)$ is consistent with data from Greater Casablanca Cancer Registry (22\%), the only population-based registry that exists in Morocco since 2007 [28]. This result is also similar to a recent study conducted at the National Institute of Oncology in Rabat (24.9\%) [6]. Other national hospital-based series have showed disparate results among women aged under 36 [3-5]. In our study, women aged under 36 represent $11.2 \%$. As our case-series is limited, we could not draw any conclusions about the frequency of early onset breast cancer in the North Moroccan region.

The young age for breast cancer diagnosis in Morocco raises the question of whether demographic, genetic or environmental factors are implicated. Young age pyramid has been invoked to explain the higher frequency compared to western countries. Moreover, absence of mass screening could be an additional factor that suggests an under-estimation of breast cancer among older women $[29,30]$. This factor, alone, is however insufficient to explain the young age for breast cancer occurrence in Morocco. The genetic component should be more explored, since genetic studies including young women are very scarce nationwide, and there is still insufficient data to provide conclusive evidence [31, 32]. In our study, the higher frequency could be explained by a recruitment bias or could simply be due to the young age of the population in this region [33].

In the absence of a national registry that covers the whole Moroccan population, the real frequency of early onset breast cancer remains to be determined. Larger studies and subsequent analyses are extremely warranted.

Morocco is an ethnically diverse North African country that comprises Arabs, Amazighs, Sub-Saharan groups, Jews and Europeans. In our series including patients native and/or inhabitant of North of Morocco, most (98.8\%) patients were Arab or Amazigh descent. These are the most frequent ethnicities in this region. Our case-series could not provide any conclusion about the contribution of these ethnic groups in BCYW. To the best of our knowledge, no data is available at the national scale about the incidence of BCYW among these different ethnic groups.

Presence of a familial background has been identified as an important risk factor for developing breast cancer at an early age [34], and to be suggestive of a hereditary 


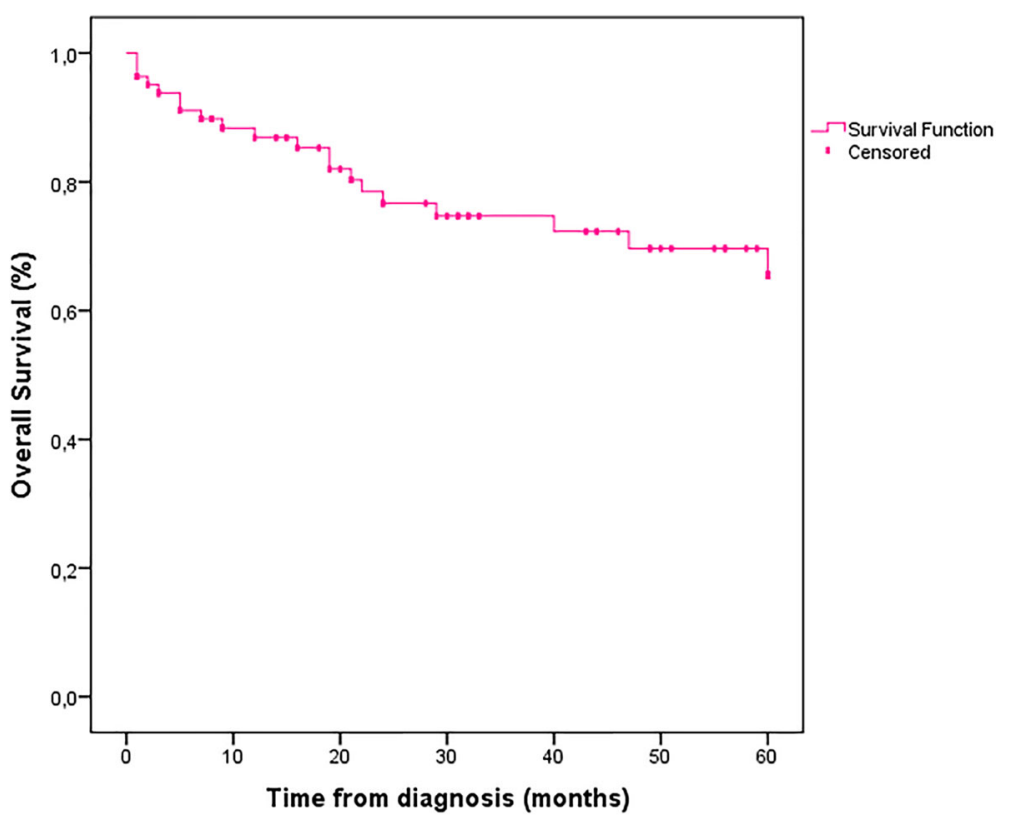

Fig. 1 Overall survival at 5 years for 82 patients

syndrome. In our study, $26 \%$ of patients had positive family history of breast or ovarian cancer, in accordance with previously reported data from Sidoni et al. [9] study (24\%). Larger series have reported much higher proportions up to $48 \%[12,16,17,35]$.

It has been recommended that young women with personal history of breast cancer should be considered for genetic counseling, and BRCA1/2 testing even when not meeting familial criteria. Published data about referral patterns showed that the proportion of young breast cancer patients who underwent BRCA1/2 testing has been increased in the last decade particularly between 2012 and 2013 [36]. This trend of genetic counseling referrals observed in developed countries has been related to the media attention to the hereditary breast cancer risk "The Angelina Jolie Effect" [37, 38]. Sadly, such data is yet to become available nationwide because the interest for genetic disorders is recent in Morocco,

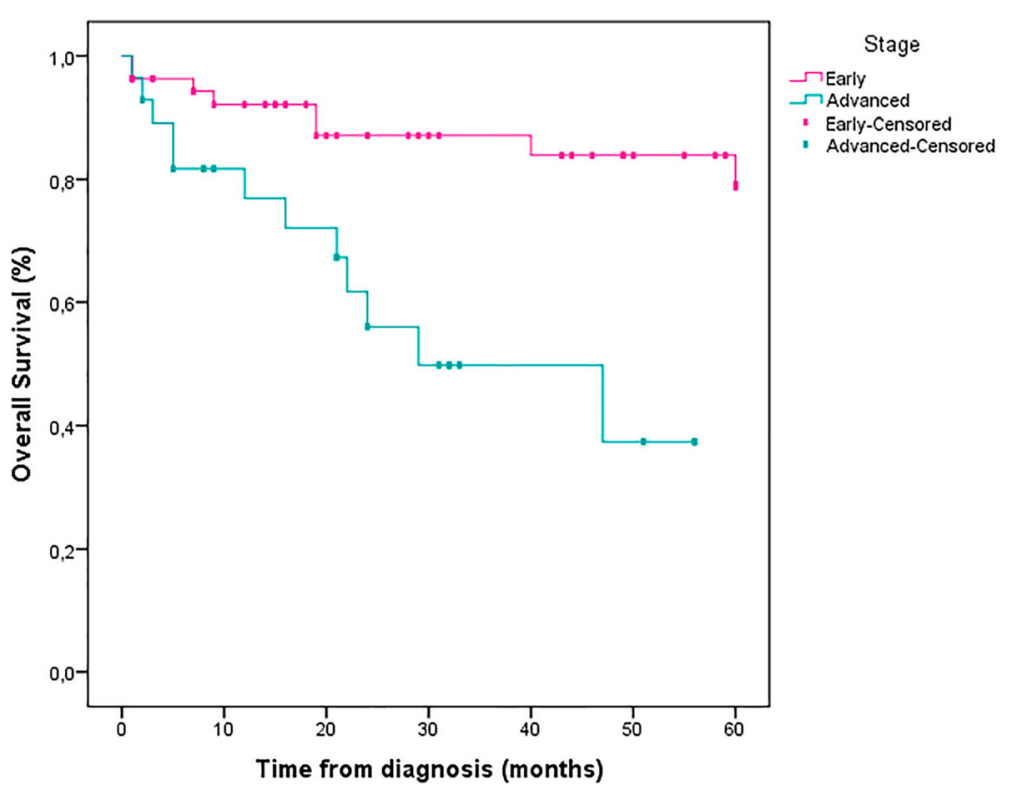

Fig. 2 Survival for 82 patients according to AJCC stages, pvalue $=0.001$ 


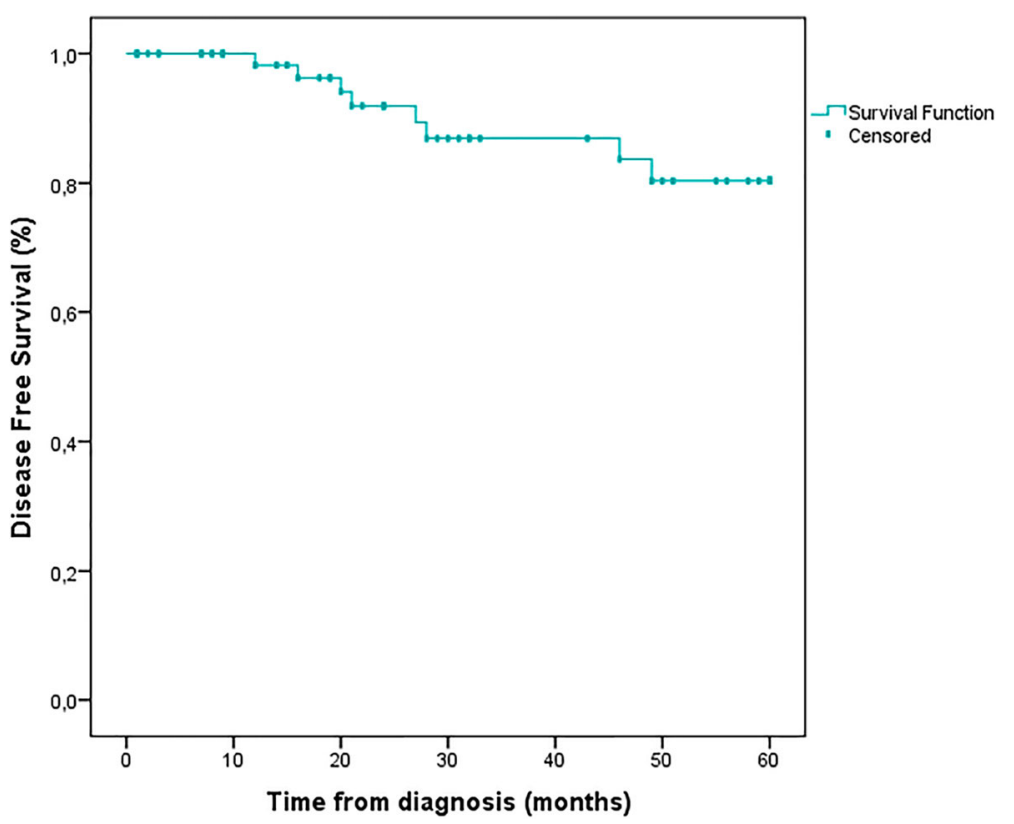

Fig. 3 Disease-free survival at 5 years for non-metastatic patients

and no medical genetic centers have been established until the end of 1990s [39].

The age cut-off used for BRCA1/2 genetic screening among young women varies widely between countries. French recommendations use a cut-off of 36 years [40], whereas the National Comprehensive Cancer Network guidelines recommend screening in women aged younger than 45 [41]. Adoption of any of these international standards should generally be tailored to each population's specificity. Decision-making is however difficult for Morocco as well as other similar countries, because no legal framework for genetic counseling services is available, besides the knowledge about mutation prevalence is still limited to provide sufficient evidence. Further genetic studies would be therefore extremely helpful in order to define the appropriate age cut-off.

Young age at onset for breast cancer has been shown to increase the risk of subsequent contralateral cancer. This higher risk might be explained somewhat by genetic susceptibility especially mutations in BRCA1 and BRCA2 genes [42]. In our series, two patients had a personal history of contralateral breast cancer. The first breast cancers were of luminal type, whereas the second cancers were triple negative. Such difference was not observed by Huo et al. [43] who described a strong concordance in hormone receptor status between primary and second breast cancers.

Diagnosis in young women has been considered difficult to establish both clinically and mammographically due to the increased breast density within this age group. Generally, this is translated into more advanced stages at disease presentation. In line with these observations, we described a diagnosis delay, but the proportion of advanced-stage disease remains much higher than that reported in western series $(34.2 \%$ Vs. 19\%) [16].

It has been reported that breast cancer occurring in younger women has more aggressive features. The tumors were more likely to be undifferentiated, with higher proliferation index, more nodal involvement, less positive hormone receptor status and with an overexpression of HER2 [9-14].

Proportion of high-grade tumors in our series (40.2\%) remains relatively low compared with western series, which reported more higher rates up to $58.9 \%$ among young women under 40 [11, 12, 15-17]. This could be explained by the presence in our study of an important rate of intermediate grade tumors (47.6\%).

Having node involvement ( $\geq 4$ nodes) is a poor prognostic factor which is considered as an indication for adjuvant chemotherapy according to the 2015 St Gallen International Consensus guidelines [44]. In previous publications, lymph node-positive disease in young women under 40 years seems to be ranged from $39.2 \%$ to $53 \%[9,11,12,15,17]$. In the current study, $58.5 \%$ of patients had positive lymph nodes.

Several studies have shown age-specific disparity in hormone receptors status [9-12, 14]. In recent series, rate of hormone-negative tumors has been around 34\% [15-17, 45]. The proportion of HER2 over-expressing tumors in published reports ranged from $15.2 \%$ to $48 \%$ $[9,15-17,45]$. In accordance with these data, we found 
that $33.8 \%$ of tumors were HR-negative and $29.2 \%$ overexpressed HER2.

Tumor biology and molecular pathways involved in early-onset breast cancers are widely unknown. Based on IHC or gene expression profiling, published data have shown that for unclear reasons younger women have tendency for more aggressive subtypes [10, 14, 16, 45]. The proportion of luminal cancers in our study is almost identical (66.2\%) to that reported by Collins et al. [16], but we have not sufficient data for Ki-67 to permit classification into types A and B. HER2 and triple negative phenotypes were found respectively in $10.8 \%$ and $23 \%$ of the cases, consistent with Keegan et al. [45] study. Clinicopathologic and prognostic features of the triple negative group diagnosed in our institution have been recently published. This study revealed that approximately two thirds $(63.6 \%)$ of the patients were nonmenopausal [46].

The choice of surgical treatment type depends mainly on risk factors of local recurrence, ratio of cosmetic/carcinological results and patient's informed decision. Young age (especially $\leq 35$ years) has been considered as risk factor for local recurrence following breastconserving surgery [47], but despite this increased risk there is a great evidence for no survival benefit for undergoing radical treatment rather than conserving surgery $[47,48]$.

We described in our study that most (61.8\%) of patients underwent radical surgery. This could be partly explained by the presence of many limitations for management of breast conserving surgery. The radiological surveillance by Magnetic Resonance Imaging (MRI) is often discussed for BCYW, as it is the most sensitive test (more than 90\%) for detecting small and/or multicentric relapse in dense breasts $[49,50]$, but unfortunately this imaging modality is still expensive, which substantially hinders better management.

Several publications have revealed that breast cancer young patients have had poor prognosis with increased risk of locoregional recurrence and lower survival [11-13, $18,19,51]$. Buckley et al. [52] reported a 5-year locoregional recurrence rate of $5.56 \%$, whereas another study by Plichta et al. [53] described a 5-year locoregional recurrence rate of $2 \%$, almost similar to that found in our series $(2.8 \%)$.

Data from the present study showed that the 5-year OS $(75.6 \%)$ was comparable to that previously reported in older series $[19,51]$, but this was still lower compared with recent reports $[17,53]$. Furthermore, this OS was much lower for patients with advanced-stage disease. Survival according to stages revealed that OS at 5 years in advanced stages was significantly inferior to that in early stages $(57.1 \%$ Vs. $85.2 \%$, pvalue $=0.001<0.05)$. Overall, the poor prognosis observed in our series may be partly explained by a substantial delayed diagnosis, but other factors are likely to be involved including the aggressive biology or potential socioeconomic factors.

The present study showed some limitations. This is a size limited case-series recruiting patients from only one health institution. As such, it could not be representative of the whole North Moroccan region. The retrospective character of some data represents another limitation. In addition, our study is conducted in the private sector, which could represent a recruitment bias.

\section{Conclusion}

Our results are in accordance with literature data reporting higher proportion of breast cancer among young Moroccan women. Larger studies are warranted to confirm our findings.

Interestingly, our ongoing genetic study for identifying germline mutations in BRCA genes would contribute to a better understanding of the genetic profile of patients involved in this series.

Consistent with published reports, we described aggressive biologic features. There was seen much higher proportion of advanced-stage disease in our study, which reflects somewhat a substantial delay in diagnosis. In terms of treatment choices, our patients underwent radical mastectomy rather than conserving surgery, which adds further challenge for these young women at the emotional and psychosocial levels, especially in the absence of a specialized psychological support.

\section{Abbreviations \\ ACR: American College of Radiology; AJCC: American Joint Committee of Cancer; BCYW: Breast cancer in young women; BI-RADS: Breast imaging- reporting and data system; Cl: Confidence interval; CISH: Chromogenic in-situ hybridization; DFS: Disease-free survival; ER: Estrogen receptor; \\ FISH: Fluorescence in situ hybridization; HER2: Human Epidermal growth factor Receptor 2; HR: Hormone Receptors; IHC: Immunohistochemistry; MRI: Magnetic resonance imaging; mSBR: Scarf-Bloom-Richardson classification modified by Elston and Elliss; NST: No special type; OS: Overall survival; PR: Progesterone receptor}

\section{Acknowledgments}

We wish to thank the team of Human Genomic Research Laboratory at the Faculty of Sciences and Techniques of Tangier especially Miss Zeineb Zian for her unconditional support and the team of Oncology Clinic AL AMAL of Tangier for their collaboration and help. Also we present our greetings to Mr. Ali Iraki for his proof reading.

\section{Funding}

The authors have no support or funding to report.

\section{Availability of data and materials \\ The datasets analyzed during the current study will be available from the corresponding author on reasonable request.}

\section{Authors' contributions}

BJ designed the study, drafted the manuscript, carried out the acquisition and collection of data, performed data analysis and interpretation. MM participated in the design of the study, helped with data analysis,

interpretation and critical revising of the manuscript. DT participated in the collection and assembly of data, performed the statistical analysis and critical revision of the manuscript. FM helped with statistical analysis and critical 
revision of the manuscript. HS, LA, BA, GNN participated in the acquisition of data and in the critical revision of the manuscript. BMM participated in the analysis and interpretation of literature data and revised critically the manuscript. All authors read, approved the final manuscript and were responsible for all aspects of the work.

\section{Ethics approval and consent to participate}

The study was approved by the Ethics Committee for Biomedical Research of the Faculty of Medicine and Pharmacy of Rabat (CERB) registered under number IORG0006594. All participants gave a written informed consent to participate in the study.

\section{Consent for publication}

Not applicable for this study.

\section{Competing interests}

The authors declare that they have no competing interests.

\section{Publisher's Note}

Springer Nature remains neutral with regard to jurisdictional claims in published maps and institutional affiliations.

\section{Author details}

${ }^{1}$ Human Genomic Research Laboratory, Faculty of Sciences and Techniques of Tangier, University Abdelmalek Essaâdi, Tangier, Morocco. ${ }^{2}$ Oncology Clinic AL AMAL of Tangier, Tangier, Morocco. ${ }^{3}$ Mathematics and Applications Laboratory, Faculty of Sciences and Techniques of Tangier, University Abdelmalek Essaâdi, Tangier, Morocco.

Received: 28 November 2016 Accepted: 31 October 2017 Published online: 09 November 2017

\section{References}

1. Ferlay J, Soerjomataram I, Ervik M, Dikshit R, Eser S, Mathers C, et al. GLOBOCAN 2012 v1.0, cancer incidence and mortality worldwide: IARC Cancer Base no. 11. Lyon: International Agency for Research on Cancer; 2013. http://globocan.iarc.fr. Accessed 10 Nov 2016.

2. Greater Casablanca Cancer Registry: 2005-2007. Edition 2012. http://www.irc ma/wp-content/uploads/2016/pdf_statistique/registre-des-cancers-gd-casa. pdf. Accessed 10 Nov 2016

3. Abahssin H, Lalya I, EL M'Rabet FZ, Ismaili N, Razine R, Adnane Tazi M, et al. Breast cancer in moroccan young women: a retrospective study. BMC Res Notes. 2010;3:1.

4. Boufettal $\mathrm{H}$, Noun M, Samouh N. Breast cancer in young patient in Morocco. Cancer Radiother. 2010;14:698-703.

5. Znati K, Bennis S, Abbass F, Akasbi Y, Chbani L, Elfatemi H, et al. Breast cancer in young patient in Morocco. Gynecol Obstet Fertil. 2014;42:149-54.

6. Slaoui M, Mouh FZ, Ghanname I, Razine R, El Mzibri M, Amrani M. Outcome of Breast Cancer in Moroccan Young Women Correlated to ClinicPathological Features, Risk Factors and Treatment: A Comparative Study of 716 Cases in a Single Institution. PLoS One. 2016;11:e0164841.

7. DeSantis C, Ma J, Bryan L, Jemal A. Breast cancer statistics, 2013. CA Cancer J Clin. 2014:64:52-62.

8. Gabriel CA, Domchek SM. Breast cancer in young women. Breast Cancer Res. 2010;12:1.

9. Sidoni A, Cavaliere A, Bellezza G, Scheibel M, Bucciarelli E. Breast cancer in young women: clinicopathological features and biological specificity. Breast. 2003;12:247-50.

10. Anders CK, Hsu DS, Broadwater G, Acharya CR, Foekens JA, Zhang Y, et al. Young age at diagnosis correlates with worse prognosis and defines a subset of breast cancers with shared patterns of gene expression. J Clin Oncol. 2008:26:3324-30.

11. Gnerlich JL, Deshpande AD, Jeffe DB, Sweet A, White N, Margenthaler JA. Elevated breast cancer mortality in women younger than age 40 years compared with older women is attributed to poorer survival in early-stage disease. J Am Coll Surg. 2009;208:341-7.

12. Bharat A, Aft RL, Gao F, Margenthaler JA. Patient and tumor characteristics associated with increased mortality in young women ( $\leq 40$ years) with breast cancer. J Surg Oncol. 2009;100:248-51.
13. Fredholm H, Eaker S, Frisell J, Holmberg L, Fredriksson I, Lindman H. Breast cancer in young women: poor survival despite intensive treatment. PLoS One. 2009;4:e7695

14. Morrison DH, Rahardja D, King E, Peng Y, Sarode VR. Tumour biomarker expression relative to age and molecular subtypes of invasive breast cancer. Br J Cancer. 2012;107:382-7.

15. Karihtala $P$, Winqvist $R$, Bloigu $R$, Jukkola-Vuorinen A. Long-term observational follow-up study of breast cancer diagnosed in women $\leq 40$ years old. Breast. 2010;19:456-61.

16. Collins LC, Marotti JD, Gelber S, Cole K, Ruddy K, Kereakoglow S, et al. Pathologic features and molecular phenotype by patient age in a large cohort of young women with breast cancer. Breast Cancer Res Treat. 2012; 131:1061-6.

17. Copson E, Eccles B, Maishman T, Gerty S, Stanton L, Cutress Rl, et al. Prospective observational study of breast cancer treatment outcomes for UK women aged 18-40 years at diagnosis: the POSH study. J Natl Cancer Inst. 2013:105:978-88.

18. De la Rochefordière A, Asselain B, Campana F, Scholl SM, Frenton J, Vilcoq $\mathrm{JR}$, et al. Age as prognostic factor in premenopausal breast carcinoma. Lancet. 1993;341:1039-43.

19. Maggard MA, O'Connell JB, Lane KE, Liu JH, Etzioni DA, Ko CY. Do young breast cancer patients have worse outcomes? J Surg Res. 2003;113:109-113.

20. Anders CK, Fan C, Parker JS, Carey LA, Blackwell KL, Klauber-DeMore N, et al. Breast carcinomas arising at a young age: unique biology or a surrogate for aggressive intrinsic subtypes? J Clin Oncol. 2011;29:e18-20.

21. Colleoni $M$, Anders CK. Debate: the biology of breast cancer in young women is unique. Oncologist. 2013;18:e13-e15.

22. De Sanjosé $\mathrm{S}$, Léoné $\mathrm{M}$, Bérez $\mathrm{V}$, Izquierdo A, Font $\mathrm{R}$, Brunet JM, et al. Prevalence of BRCA1 and BRCA2 germline mutations in young breast cancer patients: a population-based study: BRCA and breast cancer in young women. Int J Cancer. 2003;106:588-93.

23. Rouba A, Kaisi N, Al-Chaty E, Badin R, Pals G, Young C, et al. Patterns of allelic loss at the BRCA1 locus in Arabic women with breast cancer. Int $J$ Mol Med. 2000;6:565-9.

24. Uhrhammer N, Abdelouahab A, Lafarge L, Feillel V, Ben Dib A, Bignon Y-J. BRCA1 mutations in Algerian breast cancer patients: high frequency in young, sporadic cases. Int J Med Sci. 2008:5:197-202.

25. Bhikoo R, Srinivasa S, Yu T.-C, Moss D, Hill AG. Systematic review of breast cancer biology in developing countries (part 1): Africa, the Middle East, Eastern Europe, Mexico, the Caribbean and South America. Cancers. 2011;3: 2358-2381.

26. Bhikoo R, Srinivasa S, Yu T.-C, Moss D, Hill AG. Systematic review of breast cancer biology in developing countries (part 2): Asian subcontinent and South East Asia. Cancers 2011:3:2382-2401.

27. Najjar H, Easson A. Age at diagnosis of breast cancer in Arab nations. Int J Surg. 2010;8:448-52.

28. Greater Casablanca Cancer Registry:2004. Edition 2007. http://www.irc.ma/ wp-content/uploads/2016/pdf_statistique/Registre des_Cancers_de la Reegion_du_grand_Casablanca_2004.pdf. Accessed 10 Nov 2016.

29. Corbex M, Bouzbid S, Boffetta P. Features of breast cancer in developing countries, examples from North-Africa. Eur J Cancer. 2014;50:1808-18.

30. Ghiasvand R, Adami H-O, Harirchi I, Akrami R, Zendehdel K. Higher incidence of premenopausal breast cancer in less developed countries; myth or truth? BMC Cancer. 2014;14:1.

31. Laraqui A, Uhrhammer N, Lahlou-Amine I, EL Rhaffouli H, El Baghdadi J, Dehayni $\mathrm{M}$, et al. Mutation screening of the BRCA1 gene in early onset and familial breast/ovarian cancer in Moroccan population. Int J Med Sci. 2013; 10:60-7.

32. Tazzite A, Nadiffi S, Kottwitz D, El Amrani M, Jouhadi H, Benider A, et al. Specific BRCA1 gene variations amongst young Moroccan breast cancer patients. Genet Mol Res. 2014;13:791-8.

33. RGPH 2014. http://www.hcp.ma. Accessed 7 May 2017.

34. Collaborative Group on Hormonal Factors in Breast Cancer. Familial breast cancer. collaborative reanalysis of individual data from 52 epidemiological studies including 58209 women with breast cancer and 101986 women without the disease. Lancet. 2001;358:1389-99.

35. Loman N, Johannsson O, Kristoffersson U, Olsson H, Borg Á. Family history of breast and ovarian cancers and BRCA1 and BRCA2 mutations in a population-based series of early-onset breast cancer. J Natl Cancer Inst. 2001;93:1215-23. 
36. Rosenberg SM, Ruddy KJ, Tamimi RM, Gelber S, Schapira L, Come S, et al. BRCA1 and BRCA2 mutation testing in young women with breast cancer. JAMA Oncol. 2016;2:730-6.

37. Evans DG, Barwell J, Eccles DM, Collins A, Izatt L, Jacobs C, et al. The Angelina Jolie effect: how high celebrity profile can have a major impact on provision of cancer related services. Breast Cancer Res. 2014;16:1.

38. Raphael J, Verma S, Hewitt P, Eisen A. The impact of Angelina Jolie (AJ)'s story on genetic referral and testing at an academic cancer Centre in Canada. J Genet Couns. 2016;25:1309-16.

39. Teebi AS. Genetic disorders among Arab populations. 2nd ed. Berlin, Heidelberg, Germany: Springer-Verlag; 2010

40. Alran S, Rousset-Jablonski C. Particularités du cancer du sein chez la femme jeune. Réal.En Gynécologie-Obstétrique. 2013;21-26.

41. National Comprehensive Cancer Network (NCCN) Clinical Practices Guidelines in Oncology. genetic/familial high-risk assessment: breast and ovarian. Version 1.2017-2016. http://www.nccn.org. Accessed 10 Nov 2016.

42. Malone KE, Begg CB, Haile RW, Borg A, Concannon P, Tellhed L, et al. Population-based study of the risk of second primary Contralateral breast cancer associated with carrying a mutation in BRCA1 or BRCA2. J Clin Oncol. 2010;28:2404-10.

43. Huo D, Melkonian S, Rathouz PJ, Khramtsov A, Olopade Ol. Concordance in histological and biological parameters between first and second primary breast cancers. Cancer. 2011;117:907-15.

44. Coates AS, Winer EP, Goldhirsch A, Gelber RD, Gnant M, Piccart-Gebhart M, et al. Tailoring therapies-improving the management of early breast cancer: St Gallen international expert consensus on the primary therapy of early breast cancer 2015. Ann Oncol. 2015;26:1533-46.

45. Keegan TH, DeRouen MC, Press DJ, Kurian AW, Clarke CA. Occurrence of breast cancer subtypes in adolescent and young adult women. Breast Cancer Res. 2012;14:1.

46. Derkaoui T, Bakkach J, Mansouri M, Loudiyi A, Fihri M, Alaoui FZ, et al. Triple negative breast cancer in north of Morocco: clinicopathologic and prognostic features. BMC Womens Health. 2016;16:68.

47. Kroman N, Holtveg H, Wohlfahrt J, Jensen MB, Mouridsen HT, Blichert-Toft M, et al. Effect of breast-conserving therapy versus radical mastectomy on prognosis for young women with breast carcinoma. Cancer. 2004;100:688-93.

48. Vila J, Gandini S, Gentilini O. Overall survival according to type of surgery in young ( $\leq 40$ years) early breast cancer patients: a systematic meta-analysis comparing breast-conserving surgery versus mastectomy. Breast. 2015;24: $175-81$

49. Saslow D, Boetes C, Burke W, Harms S, Leach MO, Lehman CD, et al. American Cancer Society guidelines for breast screening with MRI as an adjunct to mammography. CA Cancer J Clin. 2007;57:75-89.

50. Krämer S, Schulz-Wendtland R, Hagedorn K, Bautz W, Lang N. Magnetic resonance imaging in the diagnosis of local recurrences in breast cancer. Anticancer Res. 1998;18:2159-61.

51. Chung M, Chang HR, Bland KI, Wanebo HJ. Younger women with breast carcinoma have a poorer prognosis than older women. Cancer. 1996;77:97-103.

52. Buckley JM, Coopey S, Samphao S, Specht MC, Hughes KS, Gadd M, et al. Recurrence rates and long-term survival in women diagnosed with breast cancer at age 40 and younger. J Clin Oncol. 2011;29 suppl 27:70-70.

53. Plichta JK, Rai U, Tang R, Coopey SB, Buckley JM, Gadd MA, et al. Factors associated with recurrence rates and long-term survival in women diagnosed with breast cancer ages 40 and younger. Ann Surg Oncol. 2016; 23:3212-20.

\section{Submit your next manuscript to BioMed Centra and we will help you at every step:}

- We accept pre-submission inquiries

- Our selector tool helps you to find the most relevant journal

- We provide round the clock customer support

- Convenient online submission

- Thorough peer review

- Inclusion in PubMed and all major indexing services

- Maximum visibility for your research

Submit your manuscript at www.biomedcentral.com/submit

CBiomed Central 